\title{
Efficacy and Safety of Sorafenib in a Racially Diverse Patient Population with Advanced Hepatocellular Carcinoma
}

\author{
TIMOTHY M. SCHMIDT ${ }^{1}$, LI LIU ${ }^{2}$, IVY E. ABRAHAM ${ }^{1}$, ALMAE B. UY ${ }^{3}$ and ARKADIUSZ Z. DUDEK ${ }^{4}$ \\ ${ }^{1}$ Division of Academic Internal Medicine and Geriatrics, College of Medicine, \\ ${ }^{2}$ Division of Epidemiology and Biostatistics, School of Public Health, and \\ ${ }^{3}$ University of Illinois Cancer Center, University of Illinois at Chicago, Chicago, IL, U.S.A.; \\ ${ }^{4}$ HealthPartners Cancer Care Center, St. Paul, MN, U.S.A.
}

\begin{abstract}
Background: There are few efficacy and toxicity data on sorafenib for patients treated for hepatocellular carcinoma (HCC) who are not Caucasian or Asian. Materials and Methods: A retrospective analysis was carried out on 67 patients treated with sorafenib for advanced HCC at an urban referral center. Patients were categorized by race, age, sex, status, stage, and dose. Primary outcomes were time to progression (TTP), toxicity, and treatment discontinuation by race. Results: African-Americans and Caucasians had significantly shorter TTP than patients of other races (Hispanic, Asian, and unidentified) [African-Americans: hazard ratio $(H R)=5.01, p=0.0068$; Caucasians: $H R=8.25$, $p=0.0008)$. There were no significant differences in time to toxicity $(p=0.99)$. Caucasians had the shortest time to therapy discontinuation $(p=0.0298)$. TTP was shorter for males (HR $=3.51, p=0.028)$, and longer for patients experiencing toxicity (HR=0.47, $p=0.046)$. Conclusion: Among patients treated with sorafenib for advanced HCC, non AfricanAmerican/non-Caucasian race, female sex, and toxicity were associated with significantly longer time to progression.
\end{abstract}

Hepatocellular carcinoma (HCC) is the second leading cause of cancer-related mortality worldwide (1). Although approximately $75 \%$ of the burden of disease from HCC is borne by the developing world (1), HCC incidence has also

This article is freely accessible online.

Correspondence to: Arkadiusz Z. Dudek, MD, Ph.D., HealthPartners Cancer Care Center, Professor, University of Minnesota, Suite 1161, Mail Stop 11101G, 640 Jackson Street, St. Paul, MN 55101, U.S.A. Tel: +1 651 2543321, Fax: +1 2543102, e-mail: arkadiusz.z.dudek@ healthpartners.com

Key Words: Sorafenib, race, disparities, time to progression, advanced-stage hepatocellular carcinoma. risen dramatically in the United States (2). Although chronic hepatitis B virus (HBV) infection accounts for approximately $50 \%$ of HCC worldwide (3), in the United States, the rise in incidence is thought to be due primarily to the high rates of chronic hepatitis $\mathrm{C}$ viral (HCV) infection and the rising incidence of non-alcoholic fatty liver disease, which has been shown to be a significant risk factor for development of HCC regardless of cirrhosis (4).

Although survival rates have improved in patients with HCC in the United States over the past several decades (5), most of this improvement has come from higher rates of earlystage detection due to screening of appropriate patients, improved quality of surgical resection, and the introduction of liver transplantation for patients who qualify. Unfortunately, patients with intermediate- or advanced-stage disease are not surgical candidates, and options are limited to locoregional therapies and systemic therapy. Several studies have demonstrated that racial disparities exist in outcomes for HCC. African-Americans are less likely to undergo curative surgery or receive transplantation (6), or undergo locoregional procedures compared to White patients, and have higher inhospital mortality rates (7). Due, at least in part, to fewer opportunities for advanced or curative therapies, minority patients are frequently limited to systemic chemotherapy, which is the least effective therapy available to treat HCC.

In 2007, two studies showed that sorafenib, a multi-target tyrosine kinase inhibitor, improved overall survival in HCC by approximately 3 months compared to placebo $(8,9)$. These results were recently challenged by a review of the Surveillance, Epidemiology, and End Results-Medicare database which showed an insignificant difference in 3-month mortality between patients treated with sorafenib and those treated with placebo (10). However, data are lacking for African-American and Hispanic patients, as these studies enrolled primarily Caucasian and Asian patients. In this study, a retrospective analysis was performed of patients treated with sorafenib at an urban academic medical center 
to evaluate the efficacy and toxicity of sorafenib in a racially diverse population, and determine if there were other patient characteristics that influence efficacy or toxicity of sorafenib in a racially diverse, inner city population that has historically been under-represented in clinical trials.

\section{Materials and Methods}

Study design. This was a retrospective cohort analysis of patients who were seen at the University of Illinois at Chicago Cancer Center between September 2007 and August 2016 and were treated with sorafenib for HCC diagnosis. The University of Illinois at Chicago Institutional Review Board granted an informed consent waiver approval for the retrospective chart review of patients fitting the inclusion criteria.

Retrospective data collection. The Research Informatics Department conducted a search of the electronic medical record for patients seen at the University of Illinois from September 2007 - August 2016 with a diagnosis of $\mathrm{HCC}$ who were prescribed sorafenib. Patients were excluded from analysis if they did not have at least one follow-up visit after being prescribed sorafenib. The final patient list along with the data extracted from charts were secured in a password-protected file.

Measures. Patients' electronic medical records were reviewed for the following clinical information: age at diagnosis, race, sex, etiology of cirrhosis, Barcelona Clinic Liver Cancer (BCLC) stage at diagnosis, and average daily dose of sorafenib. For race, patients were divided into categories of Caucasian, African-American, and Other, which included Asian, Hispanic, and unidentified races. Etiology of cirrhosis was divided into patients who were either positive or negative for HCV. Patients were classified as male or female based on their recorded sex in the medical record. BCLC stage was categorized as A through D, per classification by the European Association for the Study of the Liver/European Organization for Research and Treatment of Cancer definition (11). Age and average daily dose were recorded as continuous variables. The dates of diagnosis, initiation of sorafenib treatment, date of the first recorded toxicity, date of permanent discontinuation of sorafenib, date of progression of disease, and date of loss to followup, and date of death were also recorded in order to calculate the outcomes of interest. Date of progression was documented as the date recorded in the medical record, or if undocumented was determined using the New Response Evaluation Criteria In Solid Tumors (12).

The primary outcomes were time to progression (TTP), time to toxicity, and time to discontinuation of treatment among different races. TTP was calculated as the number of days from the date of treatment initiation to the date of progression. Time to toxicity was calculated as the number of days from the start of treatment to the first recorded date of toxicity. Time to discontinuation was calculated as the number of days from treatment initiation to the date at which sorafenib was permanently discontinued. Censored values were recorded using the date lost to follow-up or death if specified end points were not met.

Statistical analysis. Bivariate associations between race and other variables were examined using Chi-squared tests or Fisher's exact
Table I. Cox model results for time to progression in patients with hepatocellular carcinoma treated with sorafenib.

\begin{tabular}{|c|c|c|c|}
\hline Variable & $\begin{array}{l}\text { Estimate } \\
\text { (SE) }\end{array}$ & $\begin{array}{l}\text { Hazard ratio } \\
(95 \% \mathrm{CI})\end{array}$ & $p$-Value \\
\hline \multicolumn{4}{|l|}{ Race } \\
\hline Other & Reference & 1 & \\
\hline $\mathrm{AA}$ & $1.61(0.60)$ & $5.01(1.56-16.07)$ & 0.0068 \\
\hline Caucasian & $2.11(0.63)$ & $8.25(2.39-28.47)$ & 0.0008 \\
\hline \multicolumn{4}{|l|}{ Gender } \\
\hline Female & Reference & 1 & \\
\hline Male & $1.26(0.57)$ & $3.51(1.14-10.75)$ & 0.0281 \\
\hline \multicolumn{4}{|l|}{ HCV status } \\
\hline No HCV & Reference & 1 & \\
\hline $\mathrm{HCV}$ & $-0.91(0.47)$ & $0.40(0.16-1.01)$ & $0.0523 \ddagger$ \\
\hline \multicolumn{4}{|l|}{ Toxicity } \\
\hline No & Reference & 1 & \\
\hline Yes & $-0.76(0.40)$ & $0.47(0.22-0.98)$ & 0.0457 \\
\hline \multicolumn{4}{|c|}{ Tx Discontinuation } \\
\hline No & Reference & 1 & \\
\hline Yes & $1.27(0.76)$ & $3.57(0.80-15.88)$ & $0.0953 \ddagger$ \\
\hline
\end{tabular}

AA: African American; HCV: hepatitis $\mathrm{C}$ virus. $¥$ Results with $0.05<p<0.10$ are considered marginal due to power consideration.

tests (for categorical variables), ANOVA (for continuous variables), and log-rank tests (for time-to-event data). Confidence interval (95\% CI) estimations were provided for treatment durations, rates of toxicity, and disease progression. Multi-variate Cox regression model was employed to predict time-to-progression. Backward model selections were performed. Proportional hazard assumption was tested for all entered predictors. Results showed no violation of this assumption. Non-inferiority test was performed to compare the hazards between African-Americans and Caucasians per established methods (13). All statistical tests controlled for a type I error probability of 0.05 , with notes of marginal significance when $p$-values were less than 0.10 due to sample size and power considerations.

\section{Results}

Patient characteristics. A total of 67 patients with HCC prescribed sorafenib who were not excluded were identified within the electronic database. There were 38 AfricanAmericans, 13 Caucasians, and 16 patients of other racial groups (nine Hispanics, five Asians, and two unidentified were grouped together for power considerations). The mean age of our patients was 59.1 years, $54(81 \%)$ were males and 13 females. Patients were subdivided into those who were $\mathrm{HCV}$-positive and HCV-negative. Among the 48 patients (72\%) who were HCV-positive, 12 were also alcoholic, two were co-infected with hepatitis $\mathrm{B}$, and one was also thought to have cirrhosis due to non-alcoholic steatohepatitis. Of the 19 patients (28\%) who were seronegative for $\mathrm{HCV}$, six were infected with HBV, five had alcoholic cirrhosis, seven were diagnosed with either non-alcoholic steatohepatitis or 


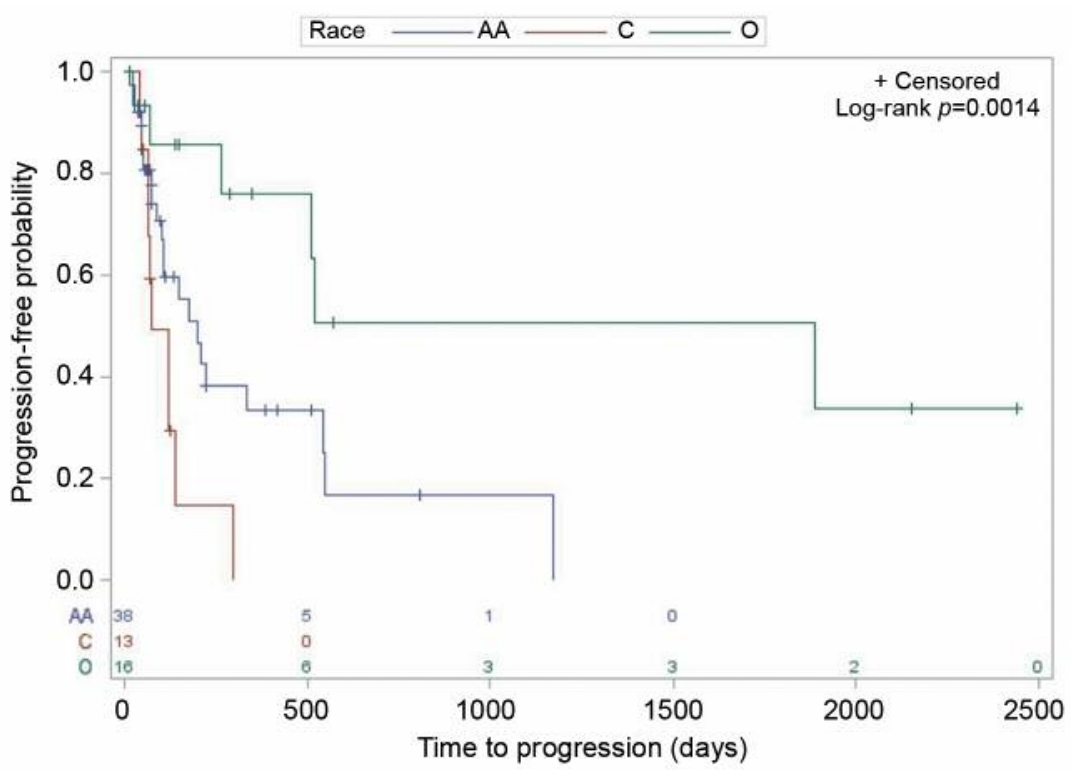

Figure 1. Product-limit estimates for progression-free survival curves. AA: African-American; C: Caucasian; O: Other race. Numbers represent number of patients in the racial group.

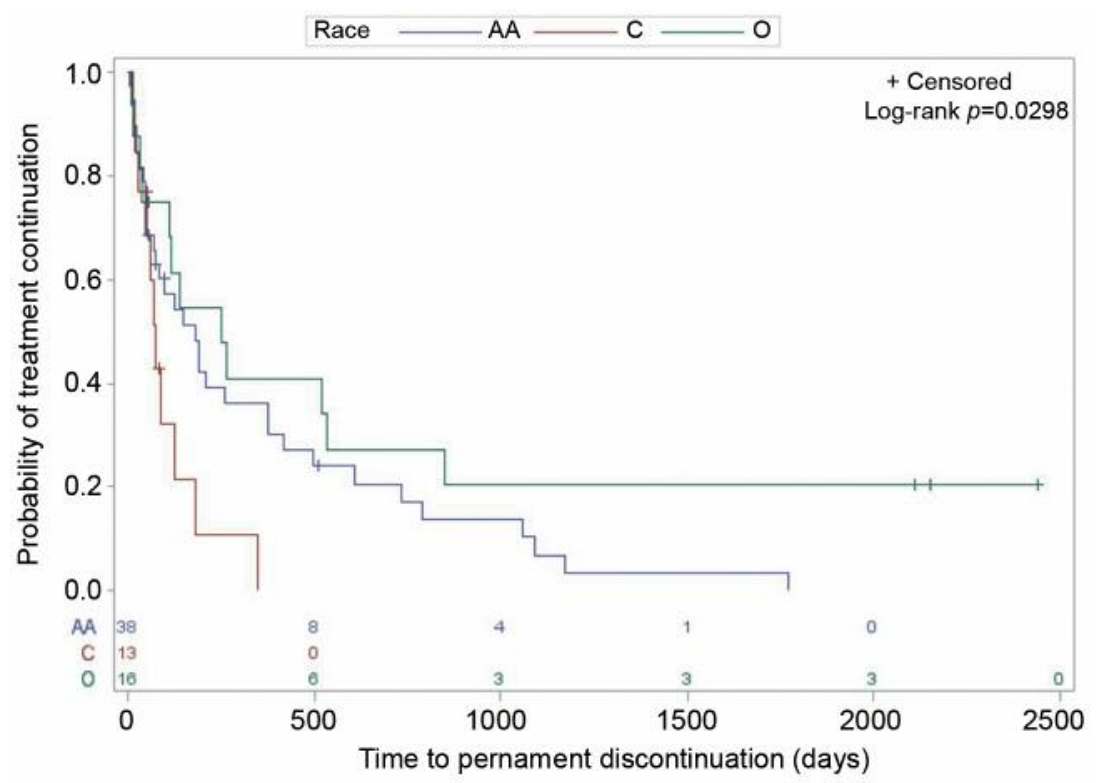

Figure 2. Kaplan-Meier curves demonstrating time to discontinuation of sorafenib treatment of patients with advanced-stage hepatocellular carcinoma. AA: African-American; C: Caucasian; O: Other race. Numbers represent number of patients in the racial group.

cryptogenic cirrhosis, and one had alcohol-and HBVassociated cirrhosis. There was a significant difference in HCV status among racial groups, with a significantly higher number of $\mathrm{HCV}$ diagnoses among African-American patients $(p=0.026)$. By the BCLC staging system, nine patients $(13 \%)$ were diagnosed at stage A, 29 patients (43\%) at stage B, and 29 patients at stage $\mathrm{C}$. The median daily dose of sorafenib among patients overall was $538.7 \mathrm{mg} /$ day (mean=543 $\mathrm{mg} /$ day, 95\% CI=487.9-598.1 mg/day), and did not differ significantly among racial groupings $(p=0.8723)$. 


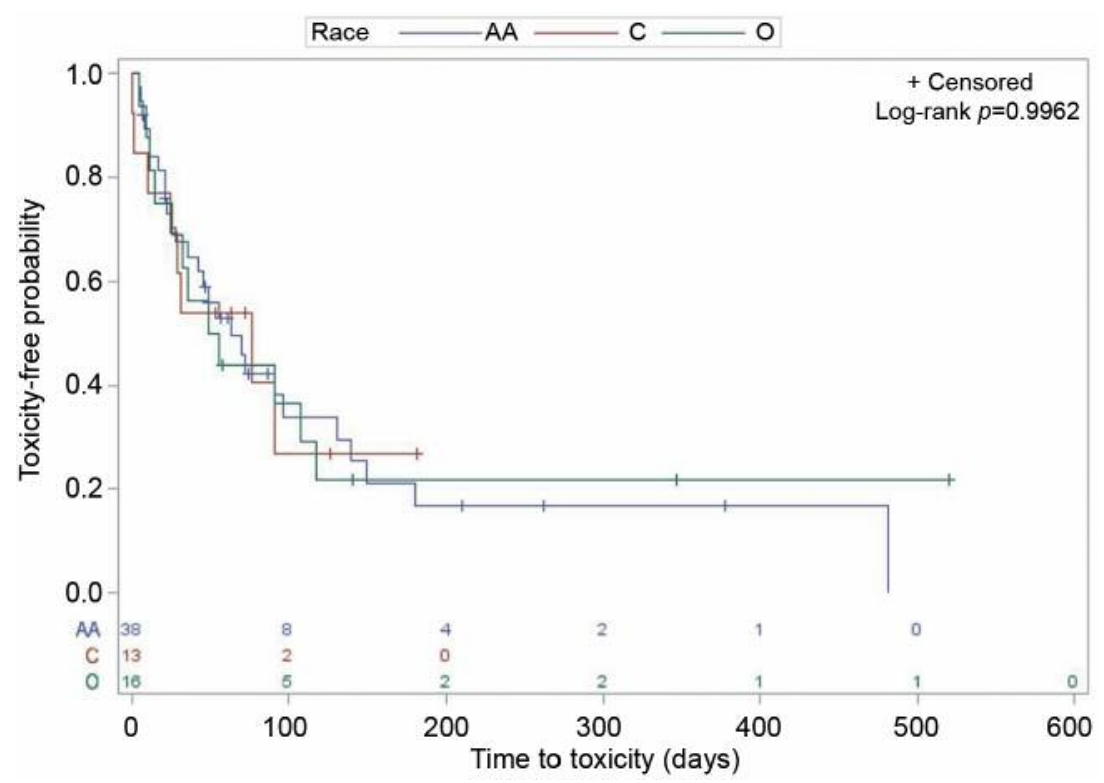

Figure 3. Kaplan-Meier curves demonstrating time to toxicity from sorafenib in patients with advanced-stage hepatocellular carcinoma. AA: African American; C: Caucasian; O: Other race. Numbers represent the number of patients in the racial group.

Primary objectives. The median TTP was estimated to be 210 days (95\% CI=109, 510 days), and there was a significant racial difference $(p=0.0014)$. The respective median progression-free times (95\% CI) were: Caucasian: 73 (64-140) days; African-American: 198 (105-546) days; 1888 days for Other races, with 10 out of 16 patients in this subgroup not experiencing disease progression at the time of the conclusion of the chart review. The product-limit curves for race-specific progression-free estimates are shown in Figure 1.

The overall median (95\% CI) treatment duration was 141 (76-210) days. However, there was a significant racial group difference $(p=0.0298)$. The median treatment duration was 76 (29-126) days for Caucasians, 180 (72-375) days for African-Americans, and 250 (36-850) days for Other races. The Kaplan-Meier curves for time to discontinuation are shown in Figure 2.

Among the 67 patients treated, $47(70.2 \%, 95 \% \mathrm{CI}=59.2-$ $80.7 \%$ ) experienced toxicity. The overall median time to toxicity was $63(95 \% \mathrm{CI}=36-91)$ days and there was no statistically significant racial difference in time to toxicity $(p=0.99)$. The Kaplan-Meier curves for time to toxicity are shown in Figure 3.

Multivariate analysis. Cox proportional hazard models were employed to identify factors associated with TTP after starting sorafenib. Results of significant factors from backward model selections are listed in Table I.

Controlling for all other factors, there were significant racial differences in TTP $(\mathrm{df}=2$, Wald chi-square $p=0.037)$.
Caucasian $(\mathrm{HR}=8.25)$ and African-American $(\mathrm{HR}=5.01)$ patients both had significantly higher hazard of experiencing disease progression compared to patients of Other races. There was no statistical difference in hazards between African-Americans and Caucasians $(\mathrm{HR}=0.61,95 \% \mathrm{CI}=0.27$ 1.37), with an upper HR boundary of 1.37 for Caucasians, the non-inferiority of African-American race relative to Caucasia was established.

Male sex was associated with significantly shorter TTP compared to females $(\mathrm{HR}=3.51,95 \% \mathrm{CI}=1.14-10.75)$. Patients who experienced toxicity to sorafenib at some time during treatment had significantly longer TTP compared to those who did not $(\mathrm{HR}=0.47, \mathrm{CI}=0.22-0.99)$. Patients who had documented HCV infection leading to development of HCC had a marginal trend towards a longer TTP compared to patients who were $\mathrm{HCV}$-negative (HR=0.40, 95\% $\mathrm{CI}=0.16-1.01)$. Discontinuing treatment due to toxicity was associated with a trend towards a shorter TTP $(\mathrm{HR}=3.57$, 95\% CI=0.80-15.88).

Variables that showed no association with TTP were patient age $(p=0.65)$, BCLC stage at time of diagnosis $(p=0.63)$, average daily dose of sorafenib during the treatment period $(p=0.89)$, and duration of treatment $(p=0.15)$.

\section{Discussion}

This retrospective study sought to examine the efficacy of sorafenib in a racially diverse urban population, and to evaluate whether there were certain patient characteristics 
that were associated with better efficacy or toxicity profiles in this diverse patient population. The primary outcomes were TTP, time to treatment toxicity, and time to permanent discontinuation of sorafenib among patients of different races. Other variables included in our analysis were age at diagnosis, sex, etiology of cirrhosis, Barcelona stage at diagnosis, and average daily dose of sorafenib.

After controlling for all other factors, our study showed that the composite racial group of those with Asian, Hispanic, and unidentified race had a significantly longer median TTP compared with African-American and Caucasian patients. In contrast to studies examining outcome disparities among African-American patients in HCC (5-7), our study demonstrated that African-American patients treated with sorafenib had non-inferior outcomes compared to Caucasians. TTP for African-American patients was 198 days compared to 73 days for Caucasians. Although this difference did not meet statistical significance, non-inferiority was established on multivariate analysis. There were no significant differences between racial groups in terms of time to toxicity. There was a significant difference between races in time to discontinuation of treatment, mirroring the difference observed in TTP among different races.

By Cox regression analysis, it was also determined that female patients had significantly longer TTP compared to male patients, and patients who experienced toxicity also had significantly longer TTP. Patients who had HCV as an etiological factor had a trend towards improved TTP, whereas having to discontinue therapy due to toxicity trended towards a shorter TTP.

The reason for the improved progression-free time for patients of Hispanic, Asian, and unidentified race treated with sorafenib compared with African-American and Caucasian patients is unclear. Studies focusing on the pharmacokinetics of tyrosine kinase inhibitors such as sorafenib indicate that multiple factors determine the metabolism of these agents, including gastrointestinal absorption (14) and activity of hepatic enzymes (15). While these variations could partially account for the different outcomes we observed in our patients, it is unlikely that drug metabolism is the only determinant of this difference, given that toxicity rates were so similar among different races. It is likely that genetic polymorphisms in cytokine profiles (16), tumor microenvironment $(17,18)$, or other factors play a significant role in the response to sorafenib, possibly explaining the significant differences in tumor response but similar toxicity profiles.

The significance of the differences in time to discontinuation mirror the differences in TTP. Although $70 \%$ of patients experienced toxicity in this study, it was easily managed in most, and was rarely associated with discontinuation of therapy. In fact, on review of our patients, almost all patients who discontinued therapy did so due to progression of disease or clinical decompensation from their underlying disease rather than drug toxicity.

Although it is desirable to avoid side-effects, the correlation between toxicity and efficacy has been welldescribed, and evidence of toxicity can intuitively be considered a surrogate marker for drug activity. Early hand-foot skin reactions have been shown to be a marker predictive for sorafenib efficacy $(19,20)$, and similar effects have been seen for other targeted therapies (21). In our study, any reported toxicity, including hand-foot skin reactions, diarrhea, malaise, or other symptoms were included in the side-effect profile of sorafenib. Our data suggest that patients who experienced any toxicity from sorafenib had significantly longer TTP compared to patients who did not report any toxic effects.

Although previous studies have come to a wide variety of conclusions regarding viral hepatitis status and outcomes in patients receiving sorafenib for HCC (22-26), our study suggests that sorafenib is more efficacious in patients with $\mathrm{HCV}$. This is consistent with a recent meta-analysis which demonstrated that sorafenib increased overall survival in HCV-positive/HBV-negative patients when compared with alternative treatments (27). The mechanism by which sorafenib may be more effective in HCC caused by HCV is unknown, but recent studies identified several biologic pathways that may be involved. Sorafenib has been shown to inhibit HCV replication (28), which reduces the expression of downstream mediators of carcinogenesis (29, 30 ), but it is unknown if sorafenib has any effect on these functions, or whether blockade of these pathways would affect outcomes. Alternatively, differences in epigenetics (31) or changes to the inflammatory milieu of carcinogenesis in the tumor stroma $(16,32)$ may be also be responsible. Further research is needed to characterize the effect of sorafenib in these pathways.

Our data showed that female patients had a longer TTP than males while on sorafenib. This is consistent with the results of a 2014 multicenter trial in Japan (33). Global epidemiological data has shown that $\mathrm{HCC}$ is more prevalent in males as compared to females, with 2- to 3-fold higher prevalence. Although the exact mechanism of this difference is likely multifactorial, there is evidence that sex hormones are involved. Male patients may also have poorer outcomes due to evidence suggesting that while androgens have been shown to potentiate carcinogenesis $(34,35)$, estrogen may have a tumor-protective effect (36). Sorafenib has been shown to modulate sex hormone expression in vitro, but it is unclear whether the difference seen in our study is reflective of gender-specific effects of sorafenib or whether it simply represents the known impact of hormonal receptors on $\mathrm{HCC}$ carcinogenesis.

Our study indicated that Barcelona stage at the time of diagnosis, age at time of diagnosis, average daily dose, and 
treatment duration were not predictive of a patient's response to sorafenib in terms of median TTP. Prior studies have shown that higher Barcelona stage and Childs-Pugh score of $\mathrm{B}$ was indicative of poorer prognosis in patients treated with sorafenib $(37,38)$. Of note, these differences were noted in Japanese cohorts of patients, and may not be applicable to urban populations in the United States.

Age has not been shown to be a factor predictive of HCC progression nor of response of HCC to sorafenib. Multiple studies examining the use of sorafenib in the elderly have not shown any significant difference in response to treatment $(39,40)$.

Our study showed that the average daily dose had no effect on TTP, that is consistent with the findings of previous research. Studies evaluating the dosing of sorafenib $(25,37$, $41,42)$ have all shown that progression-free times are independent of sorafenib dose or schedule. Our study supports the conclusion that if a patient can tolerate any administration, the absolute dose of sorafenib does not seem to correlate with outcome.

One of the strengths of our study was that it was inclusive of all patients who were treated with sorafenib for advanced HCC at one major urban hospital. It also showed the variability with which the drug was prescribed clinically, lending further insight into its tolerability and effectiveness. Moreover, most of the patients included were African-American, providing significant information on an important minority patient population that has been under-represented in previous studies that focused only on European and Asian populations. Our study also has several important limitations. Importantly, it was a retrospective analysis, therefore it is impossible to draw conclusions regarding causality. In addition, the small sample size limits the statistical power of the study, and conduction at a single center limits its external validity. There were large differences in sample size among racial categories, which required the creation of a composite 'Other' racial category. Ideally, we would have been able to separate Asian and Hispanic patients, but the small sample size made it difficult to draw conclusions using separate racial categories.

This retrospective analysis suggests that there are racial differences in the efficacy of sorafenib, and that sorafenib may be more efficacious in patients of Asian/Hispanic races. Our data also agree with the preponderance of evidence that female sex, experiencing toxicity (pharmacodynamics factor), and $\mathrm{HCV}$ are associated with better outcomes in patients treated with sorafenib for advanced HCC. Although disparities in HCC outcomes persist, our data suggest that the progression-free time of patients treated with sorafenib is at least as good, or better for non-Caucasian patients compared to Caucasian ones. Although the methodology of this study limits its applicability to broader clinical practice, secondary outcomes evaluated on multivariate analysis are consistent with results of prior studies, and our results suggest that a larger, prospective analysis of racial outcomes of sorafenib is required to provide oncologists with better information on the efficacy and toxicity of sorafenib in minority communities.

\section{Acknowledgements}

The Authors thank Gowri Ramadas, MD and Stephanie Berg, MD for data collection, and James P. Zacny, Ph.D. for editorial support.

\section{References}

1 GLOBOCAN. International Agency for Research on Cancer (IARC). Available at: http://www-dep.iarc.fr., 2012.

2 Mittal S and El-Serag HB: Epidemiology of HCC: Consider the population. J Clin Gastroenterol 47: S2-S6, 2013.

3 El-Serag HB: Hepatocellular carcinoma. N Engl J Med 365: 1118-1127, 2011.

4 Piscaglia F, Svegliati-Baroni G, Barchetti A, Pecorelli A, Marinelli S, Tiribelli C, Bellentani S and HCC-NAFLD Italian Study Group: Clinical patterns of hepatocellular carcinoma in nonalcoholic fatty liver disease (NAFLD): A multicenter prospective study. Hepatology 63: 827-838, 2016.

5 Artinyan A, Mailey B, Sanchez-Luege N, Khalili J, Sun CL, Bhatia S, Wagman LD, Nissen N, Colquhoun SD and Kim J: Race, ethnicity, and socioeconomic status influence the survival of patients with hepatocellular carcinoma in the United States. Cancer 116: 1367-1377, 2010.

6 Hoehn RS, Hanseman DJ, Wima K, Ertel AE, Paquette IM, Abbott DE and Shah SA: Does race affect management and survival in hepatocellular carcinoma in the United States? Surgery 158: 1244-1251, 2015.

7 Rajbhandari R, Simon RE, Chung RT and Ananthakrishnan AN: Racial disparities in inhospital outcomes for hepatocellular carcinoma in the United States. Mayo Clin Proc 91: 1173-1182, 2016.

8 Llovet JM, Ricci S, Mazzaferro V, Hilgard P, Gane E, Blanc JF, de Oliveira AC, Santoro A, Raoul JL, Forner A, Schwartz M, Porta C, Zeuzem S, Bolondi L, Greten TF, Galle PR, Seitz JF, Borbath I, Häussinger D, Giannaris T, Shan M, Moscovici M, Voliotis D, Bruix J and SHARP Investigators Study Group: Sorafenib in advanced hepatocellular carcinoma. N Engl J Med 359: 378-390, 2008

9 Cheng AL, Kang YK, Chen Z, Tsao CJ, Qin S, Kim JS, Luo R, Feng J, Ye S, Yang TS, Xu J, Sun Y, Liang H, Liu J, Wang J, Tak WY, Pan H, Burock K, Zou J, Voliotis D and Guan Z: Efficacy and safety of sorafenib in patients in the Asia-Pacific region with advanced hepatocellular carcinoma: a phase III randomised, double-blind, placebo-controlled trial. Lancet Oncol 10: 25-34, 2009.

10 Sanoff HK, Chang Y, Lund JL, O’Neil BH and Dusetzina SB: Sorafenib effectiveness in advanced hepatocellular carcinoma. Oncologist 21: 1113-1120, 2016.

11 European Association For The Study Of The Liver; European Organisation for Research and Treatment Of Cancer: EASLEORTC clinical practice guidelines: management of hepatocellular carcinoma. J Hepatol 56: 908-943, 2012.

12 Eisenhauer EA, Therasse P, Bogaerts J, Schwartz LH, Sargent D, Ford R, Dancey J, Arbuck S, Gwyther S, Mooney M, 
Rubinstein L, Shankar L, Dodd L, Kaplan R, Lacombe D and Verweij J: New response evaluation criteria in solid tumours: revised RECIST guideline (version 1.1). Eur J Cancer 45: 228$247,2009$.

13 U.S. Department of Health and Human Services, FDA, CDER, CBER: Non-inferiority clinical trials to establish effectiveness: Guidance of industry. November 2016.

14 Josephs DH, Fisher DS, Spicer J and Flanagan RJ: Clinical pharmacokinetics of tyrosine kinase inhibitors: implications for therapeutic drug monitoring. Ther Drug Monit 35: 562-587, 2013.

15 Minami H, Kawada K, Ebi H, Kitagawa K, Kim YI, Araki K, Mukai H, Tahara M, Nakajima $\mathrm{H}$ and Nakajima K: Phase I and pharmacokinetic study of sorafenib, an oral multikinase inhibitor, in Japanese patients with advanced refractory solid tumors. Cancer Sci 99: 1492-1498, 2008.

16 Dondeti MF, El-Maadawy EA and Talaat RM: Hepatitis-related hepatocellular carcinoma: Insights into cytokine gene polymorphisms. World J Gastroenterol 22: 6800-6816, 2016.

17 Qin C, Cao Q, Li P, Wang S, Wang J, Wang M, Chu H, Zhou L, Li X, Ye D, Zhang H, Huang Y, Dong B, Sun X, Zou Q, Cai H, Sun L, Zhu J, Liu F, Ji J, Cui L, Wang X, Zhou H, Zhao H, Wu B, Chen J, Jiang M, Zhang Z, Shao P, Ju X and Yin C: The influence of genetic variants of sorafenib on clinical outcomes and toxic effects in patients with advanced renal cell carcinoma. Sci Rep 6: 20089, 2016.

18 Hernandez-Gea V, Toffanin S, Friedman SL and Llovet JM: Role of the microenvironment in the pathogenesis and treatment of hepatocellular carcinoma. Gastroenterol 144: 512-527, 2013.

19 Vincenzi B, Santini D, Russo A, Addeo R, Giuliani F, Montella L, Rizzo S, Venditti O, Frezza AM, Caraglia M, Colucci G, Del Prete $\mathrm{S}$ and Tonini G: Early skin toxicity as a predictive factor for tumor control in hepatocellular carcinoma patients treated with sorafenib. Oncologist 15: 85-92, 2010.

20 Reig M, Torres F, Rodriguez-Lope C, Forner A, LLarch N, Rimola J, Darnell A, Ríos J, Ayuso C and Bruix J: Early dermatologic adverse events predict better outcome in HCC patients treated with sorafenib. J Hepatol 61: 318-324, 2014.

21 Dionísio de Sousa IJ, Ferreira J, Rodrigues J, Bonito N, Jacinto P, Marques M, Ribeiro J, Pais A and Gervásio H: Association between bevacizumab-related hypertension and response to treatment in patients with metastatic colorectal cancer. ESMO Open 1: e000045, 2016.

22 Bruix J, Raoul JL, Sherman M, Mazzaferro V, Bolondi L, Craxi A, Galle PR, Santoro A, Beaugrand M, Sangiovanni A, Porta C, Gerken G, Marrero JA, Nadel A, Shan M, Moscovici M, Voliotis D and Llovet JM: Efficacy and safety of sorafenib in patients with advanced hepatocellular carcinoma: Subanalyses of a phase III trial. J Hepatol 57: 821-829, 2012.

23 Shen A, Tang C, Wang Y, Chen Y, Yan X, Zhang C, Liu R, Wei $\mathrm{X}$, Zhu Y, Zhang $\mathrm{H}$ and $\mathrm{Wu} \mathrm{Z}$ : A systematic review of sorafenib in Child-Pugh A patients with unresectable hepatocellular carcinoma. J Clin Gastroenterol 47: 871-880, 2013.

24 Peixoto RD, Renouf DJ, Gill S, Cheung WY and Lim HJ: Relationship of ethnicity and overall survival in patients treated with sorafenib for advanced hepatocellular carcinoma. J Gastrointest Oncol 5: 259-264, 2014.

25 Yada M, Masumoto A, Motomura K, Tajiri H, Morita Y, Suzuki $\mathrm{H}$, Senju $\mathrm{T}$ and Koyanagi $\mathrm{T}$ : Indicators of sorafenib efficacy in patients with advanced hepatocellular carcinoma. World $\mathrm{J}$ Gastroenterol 20: 12581-12587, 2014.
26 Inghilesi AL, Gallori D, Antonuzzo L, Forte P, Tomcikova D, Arena U, Colagrande S, Pradella S, Fani B, Gianni E, Boni L, Laffi G, Di Costanzo F and Marra F: Predictors of survival in patients with established cirrhosis and hepatocellular carcinoma treated with sorafenib. World J Gastroenterol 20: 786-794, 2014.

27 Jackson R, Psarelli EE, Berhane S, Khan H and Johnson P: Impact of viral status on survival in patients receiving sorafenib for advanced hepatocellular cancer: A meta-analysis of randomized phase III trials. J Clin Oncol 35: 622-628, 2017.

28 Himmelsbach K, Sauter D, Baumert TF, Ludwig L, Blum HE and Hildt E: New aspects of an anti-tumour drug: sorafenib efficiently inhibits HCV replication. Gut 58: 1644-1653, 2009.

29 Gong G, Waris G, Tanveer R and Siddiqui A: Human hepatitis $\mathrm{C}$ virus NS5A protein alters intracellular calcium levels, induces oxidative stress, and activates STAT-3 and NF-kappa B. Proc Natl Acad Sci USA 98: 9599-9604, 2001.

30 Wang Y, Jiang Y, Zhou J, Song W, Li J, Wang M, Chen J, Xu R, Zhang J, Ma F, Chen YH and Ma Y: Hepatitis C virus promotes hepatocellular carcinogenesis by targeting TIPE2, a new regulator of DNA damage response. Tumour Biol 37: 15265$15274,2016$.

31 Nishida N, Nagasaka T, Nishimura T, Ikai I, Boland CR and Goel A: Aberrant methylation of multiple tumor suppressor genes in aging liver, chronic hepatitis, and hepatocellular carcinoma. Hepatology 47: 908-918, 2008.

32 Zhang YH, Yan HQ, Wang F, Wang YY, Jiang YN, Wang YN and Gao FG: TIPE2 inhibits TNF- $\alpha$-induced hepatocellular carcinoma cell metastasis via Erk1/2 down-regulation and NF-kB activation. Int J Oncol 46: 254-264, 2015.

33 Takeda H, Nishikawa H, Osaki Y, Tsuchiya K, Joko K, Ogawa C, Taniguchi H, Orito E, Uchida Y, Izumi N and Japanese Red Cross Liver Study Group: Clinical features associated with radiological response to sorafenib in unresectable hepatocellular carcinoma: a large multicenter study in Japan. Liver Int 35: 1581-1589, 2015.

34 Bolton EC, So AY, Chaivorapol C, Haqq CM, Li H and Yamamoto KR: Cell-and gene-specific regulation of primary target genes by the androgen receptor. Genes Dev 21: 20052017, 2007.

$35 \mathrm{Li}$ Z, Tuteja G, Schug J and Kaestner KH: Foxa1 and Foxa2 are essential for sexual dimorphism in liver cancer. Cell 148: 72-83, 2012.

36 Yeh SH and Chen PJ: Gender disparity of hepatocellular carcinoma: the roles of sex hormones. Oncology 78(Suppl 1): 172-179, 2010.

37 Song T, Zhang W, Wu Q, Kong D and Ma W A single center experience of sorafenib in advanced hepatocellular carcinoma patients: evaluation of prognostic factors. Eur J Gastroenterol Hepatol 23: 1233-1238, 2011.

38 Nakano M, Tanaka M, Kuromatsu R, Nagamatsu H, Tajiri N, Satani M, Niizeki T, Aino H, Okamura S, Iwamoto H, Shimose S, Shirono T, Koga H, Torimura T and Kurume Liver Cancer Study Group of Japan: Sorafenib for the treatment of advanced hepatocellular carcinoma with extrahepatic metastasis: a prospective multicenter cohort study. Cancer Med 4: 1836-1843, 2015.

39 Di Costanzo GG, Tortora R, De Luca M, Galeota Lanza A, Lampasi F, Tartaglione MT, Picciotto FP, Imparato M, Mattera $\mathrm{S}$, Cordone $\mathrm{G}$ and Ascione A: Impact of age on toxicity and efficacy of sorafenib-targeted therapy in cirrhotic patients with hepatocellular carcinoma. Med Oncol 30: 446, 2013. 
40 Montella L, Addeo R, Cennamo G, Vincenzi B, Palmieri R, Sperlongano P, Sperlongano R, Iodice P, Russo P and Del Prete S: Sorafenib in elderly patients with advanced hepatocellular carcinoma: a case series. Oncology 84: 265-272, 2013.

41 Iavarone M, Cabibbo G, Piscaglia F, Zavaglia C, Grieco A, Villa $\mathrm{E}$, Cammà $\mathrm{C}$, Colombo $\mathrm{M}$ and SOFIA (SOraFenib Italian Assessment) study group: Field-practice study of sorafenib therapy for hepatocellular carcinoma: a prospective multicenter study in Italy. Hepatology 54: 2055-2063, 2011.
42 Kim JE, Ryoo BY, Ryu MH, Chang HM, Suh DJ, Lee HC, Lim YS, Kim KM and Kang YK: Sorafenib dose escalation in the treatment of advanced hepatocellular carcinoma. Oncology 82: 119-125, 2012.

Received May 4, 2018

Revised May 31, 2018

Accepted June 1, 2018 